Please do not remove this page

RMIT

UNIVERSITY

\title{
Enhanced tunability of magnetron sputtered Ba0.5Sr 0.5TiO3 thin films on c-plane sapphire substrates
}

Fardin, Ernest; Holland, Anthony; Reichart, Patrick; Ghorbani, Kamran

https://researchrepository.rmit.edu.au/esploro/outputs/9921862906701341/filesAndLinks?institution=61RMIT_INST\&index=null

Fardin, E., Holland, A., Reichart, P., \& Ghorbani, K. (2006). Enhanced tunability of magnetron sputtered $\mathrm{Ba0.5Sr} 0.5 \mathrm{TiO} 3$ thin films on c-plane sapphire substrates. Applied Physics Letters, 89(2), 1-3.

https://doi.org/10.1063/1.2220530

Published Version: https://doi.org/10.1063/1.2220530

Repository homepage: https://researchrepository.rmit.edu.au

(C) 2006 American Institute of Physics.

Downloaded On 2023/04/26 19:25:26 +1000

Please do not remove this page 


\title{
Enhanced tunability of magnetron sputtered $\mathrm{Ba}_{0.5} \mathrm{Sr}_{0.5} \mathrm{TiO}_{3}$ thin films on c-plane sapphire substrates
}

\author{
E. A. Fardin, ${ }^{\text {a) }}$ A. S. Holland, and K. Ghorbani \\ School of Electrical and Computer Engineering, RMIT University, Melbourne, Victoria 3001, Australia \\ P. Reichart \\ School of Physics, Microanalytical Research Centre, The University of Melbourne, Parkville, \\ Victoria 3010, Australia
}

(Received 8 February 2006; accepted 22 May 2006; published online 10 July 2006)

\begin{abstract}
Thin films of $\mathrm{Ba}_{0.5} \mathrm{Sr}_{0.5} \mathrm{TiO}_{3}$ (BST) were deposited on $c$-plane (0001) sapphire by rf magnetron sputtering and investigated by complementary materials analysis methods. Microwave properties of the films, including tunability and $Q$ factor were measured from 1 to $20 \mathrm{GHz}$ by patterning interdigital capacitors (IDCs) on the film surface. The tunability is correlated with texture, strain, and grain size in the deposited films. An enhanced capacitance tunability of 56\% at a bias field of $200 \mathrm{kV} / \mathrm{cm}$ and total device $Q$ of more than 15 (up to $20 \mathrm{GHz}$ ) were achieved following postdeposition annealing at $900{ }^{\circ} \mathrm{C}$. (C) 2006 American Institute of Physics.
\end{abstract}

[DOI: 10.1063/1.2220530]

Ferroelectric thin films have received much attention recently as dielectric materials for electronically tunable microwave components, due to their electric field dependent permittivity. $\mathrm{Ba}_{x} \mathrm{Sr}_{1-x} \mathrm{TiO}_{3}$ (BST) is one of the most promising of these materials, with a high dielectric tunability and relatively low losses at microwave frequencies. ${ }^{1}$ While the structural and microwave properties of BST films employing $\mathrm{MgO}, \mathrm{LaAlO}_{3}, \mathrm{Pt} / \mathrm{TiO}_{2} / \mathrm{SiO}_{2} / \mathrm{Si}$, or $\mathrm{Pt} / \mathrm{Al}_{2} \mathrm{O}_{3}$ as the growth substrate have been reported in detail, ${ }^{2-4}$ comparatively little is known about the properties of BST thin films grown directly on $c$-plane sapphire, despite the excellent microwave properties of this material. Sapphire is a relatively low cost substrate, with very low $\operatorname{loss}^{5}\left(\tan \delta=1 \times 10^{-4}\right.$ at $\left.10 \mathrm{GHz}\right)$ and a high dielectric constant, which is useful for circuit size reduction.

Preparation of high quality BST films by rf magnetron sputtering has been demonstrated in several reports. ${ }^{3,4,6}$ It is well known that the total process gas $\left(\mathrm{Ar}+\mathrm{O}_{2}\right)$ pressure affects the stoichiometry of perovskite oxide films of the form $\mathrm{ABO}_{3}$, therefore (in the case of BST) influencing the microwave properties, such as tunability and $Q$ factor. Control of the $A$ to $B$ site ratio, expressed as $(\mathrm{Ba}+\mathrm{Sr}) / \mathrm{Ti}$, is particularly important for achieving favorable electrical properties. ${ }^{1}$ In order to determine the effect of the process gas pressure on the stoichiometry of BST films on sapphire, a series of depositions were carried out with process pressures in the range of 5-40 mTorr. Rutherford backscattering spectroscopy (RBS) and x-ray photoelectron spectroscopy (XPS) were used for film characterization.

BST thin films described in this work were sputtered from a stochiometric $100 \mathrm{~mm}$ diameter $\mathrm{Ba}_{0.5} \mathrm{Sr}_{0.5} \mathrm{TiO}_{3}$ target supplied by Williams Advanced Materials. An on-axis sputtering configuration was employed, with a target-substrate distance of $60 \mathrm{~mm}$ and sputtering gas mixture of $90 \% \mathrm{Ar}$ and $10 \% \mathrm{O}_{2}$. Prior to deposition, the sapphire substrates were rinsed in acetone, isopropanol and de-ionized water. The target was presputtered without any sample in the chamber for

\footnotetext{
a) Author to whom correspondence should be addressed; electronic mail:
} efardin@ieee.org
$8 \mathrm{~h}$ to remove any surface contamination. Initial depositions were then performed at 5, 10, 20, 30, and 40 mTorr, while the rf forward power, deposition temperature, and deposition time were maintained at $90 \mathrm{~W}, 625^{\circ} \mathrm{C}$, and $30 \mathrm{~min}$, respectively.

Interdigital capacitors (IDCs) were fabricated on the BST films in a three step process. First, a seed layer composed of $20 \mathrm{~nm} \mathrm{Ti}, 30 \mathrm{~nm} \mathrm{Ni}$, and $50 \mathrm{~nm} \mathrm{Au}$ was patterned on the samples by liftoff. Next, a $2.5 \mu \mathrm{m}$ Au layer was electroplated, using thick photoresist to define the plated region. Finally, the nonplated seed layer was removed by wet etching. A series of IDCs with different electrode dimensions was realized, wherein the gap between the interdigital fingers ranged from $2-8 \mu \mathrm{m}$ and the finger length from $90-130 \mu \mathrm{m}$; the finger width was fixed at $5 \mu \mathrm{m}$. Each IDC had two sets of interdigital electrodes, and was designed for probing in a $200 \mu \mathrm{m}$ pitch ground-signal-ground (GSG) configuration.

The thickness and composition of each BST film was determined from RBS measurements using $2 \mathrm{MeV}$ He ions at the Melbourne 5 MV Pelletron accelerator. A lower deposition rate was observed at higher process gas pressures, as shown in Fig. 1(a). Figure 1 also shows the variation in film composition with deposition pressure. Importantly, films deposited at 5-30 mTorr are found to be significantly oxygen deficient. The stoichiometry of the target is replicated closely with a 40 mTorr process pressure, although the film is slightly $\mathrm{Ti}$ and oxygen deficient. Because of the Al background from the sapphire substrate, the accuracy of the oxygen determination is less than that of the $\mathrm{Ba}, \mathrm{Sr}$, and Ti.

Figure 2 shows the $\mathrm{Ba} 3 d_{5 / 2}$ XPS peaks for each film and for a powder sample taken from the sputtering target. The measurements were performed on a MicroLab 310-F instrument with $\mathrm{Al} K \alpha$ radiation $(1486.6 \mathrm{eV})$ and a takeoff angle of $90^{\circ}$. Compensation for sample charging was performed by comparison with the adventitious C $1 s$ peak at $284.6 \mathrm{eV}$. A fit to the measured data was performed using three separate peaks centered at $780.5 \mathrm{eV}$ (Ba1), $779 \mathrm{eV}(\mathrm{Ba} 2)$, and $777.9 \mathrm{eV}(\mathrm{Ba} 3)$. The decomposition of the $\mathrm{Ba} 3 d_{5 / 2}$ level into two peaks centered at 780.5 and $779 \mathrm{eV}$ has been previously 

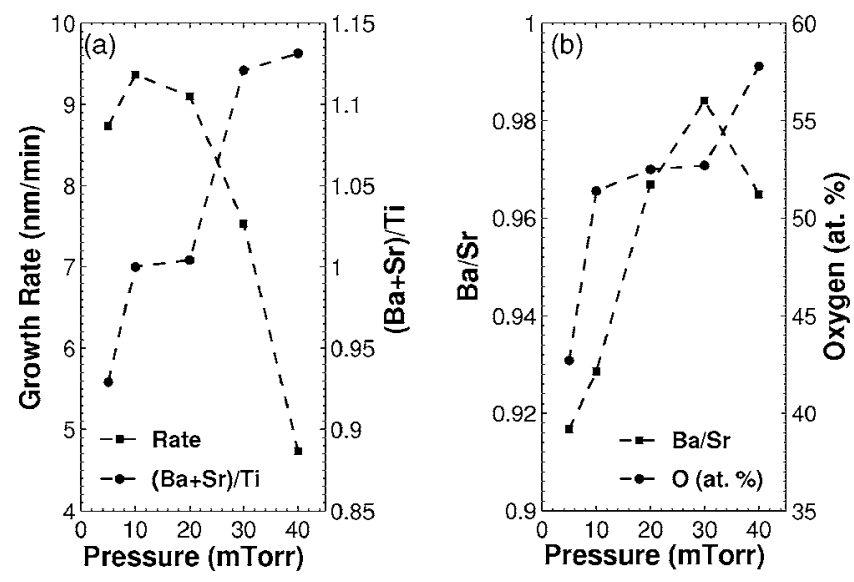

FIG. 1. (a) BST film growth rate and $(\mathrm{Ba}+\mathrm{Sr}) / \mathrm{Ti}$ ratio and (b) $\mathrm{Ba} / \mathrm{Sr}$ ratio and oxygen incorporation as a function of total process gas pressure $\left(\mathrm{Ar}+\mathrm{O}_{2}\right)$.

reported, ${ }^{7}$ wherein the $\mathrm{Ba} 2$ peak is attributed to the perovskite phase of BST, and the higher energy Ba1 peak is related to a thin decomposed surface layer that forms when the film is exposed to atmosphere. In order to obtain an accurate fit to the measured data, an additional peak at $777.9 \mathrm{eV}$ (Ba3) was required. This lower energy $\mathrm{Ba} 3$ peak could be caused by weaker $\mathrm{Ba}-\mathrm{O}$ bonds related to oxygen deficiency. ${ }^{7}$ When correlated with the RBS data in Fig. 1(b), a strong Ba3 peak at $\sim 778 \mathrm{eV}$ is indicative of oxygen deficiency in the film. The low intensity of the Ba1 peak, compared to other published results ${ }^{7,8}$ may be due to the $90^{\circ}$ takeoff angle, which will lower the contribution of the sample surface to the XPS signal.

The crystal structure of the BST films was examined using a Bruker D8 Discovery x-ray diffraction (XRD) instrument. Films deposited at $625^{\circ} \mathrm{C}$ were single phase and showed (110) preferred orientation at all process gas pressures, as shown in Fig. 3(a) for the 40 mTorr sample. As the process gas pressure increases, a trend of decreasing lattice parameter was observed. This is likely due to higher oxygen

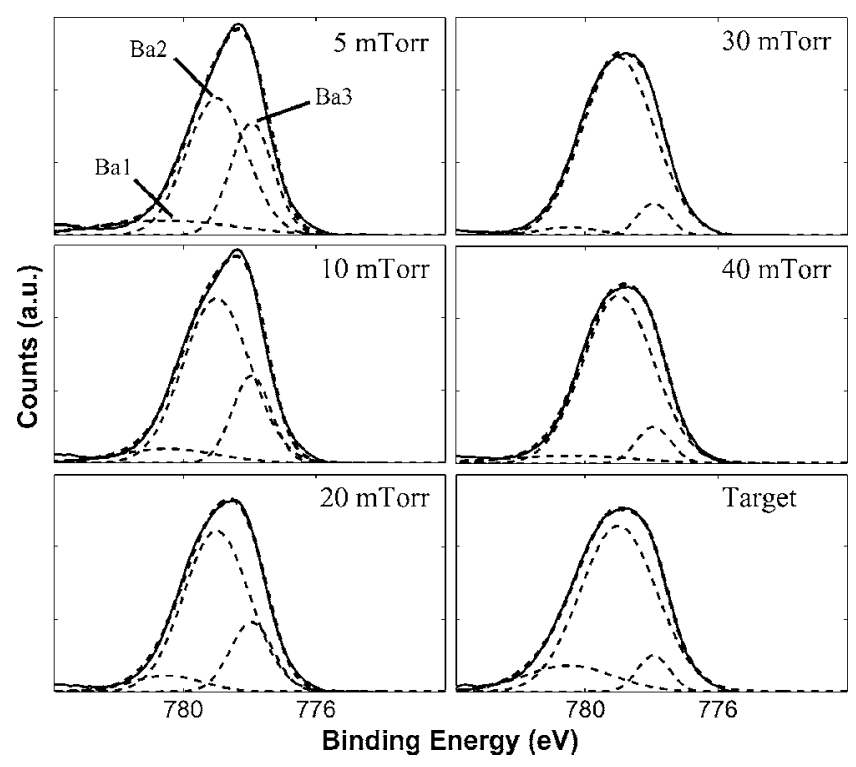

FIG. 2. Measured and fitted XPS spectra for Ba $3 d_{5 / 2}$ energy level, as a function of process gas pressure $\left(\mathrm{Ar}+\mathrm{O}_{2}\right)$, for $625^{\circ} \mathrm{C}$ substrate temperature.

The XPS spectrum for the sputtering target material is also shown. bed the parasitic inductance, capacitance, and resistance as-
Downloaded 19 Nov 2008 to 131.170.90.3. Redistribution subject to AlP license or copyright; see http://apl.aip.org/apl/copyright.jsp

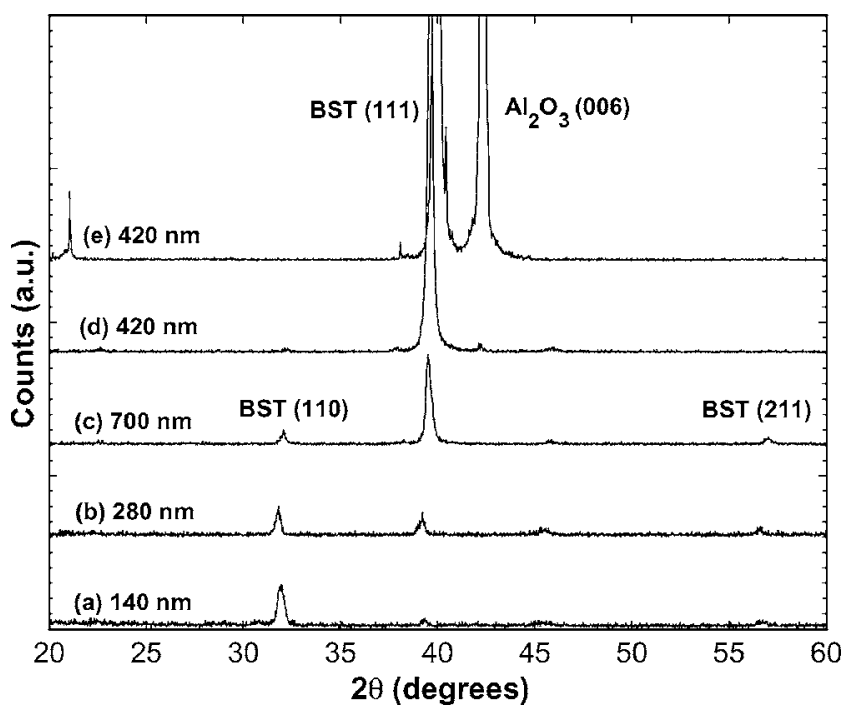

FIG. 3. XRD patterns of BST thin films deposited at 40 mTorr with substrate temperature (a) $625^{\circ} \mathrm{C}$ and (b)-(e) $700{ }^{\circ} \mathrm{C}$. Film thickness is also indicated. The sample shown at (d) was preannealed at $700{ }^{\circ} \mathrm{C}$ in $\mathrm{Ar} / \mathrm{O}_{2}$ 1:9 inside the deposition chamber for $60 \mathrm{~min}$ prior to sputtering the film. After a $2 \mathrm{~h}$ postdeposition anneal of sample (d) in air at $900^{\circ} \mathrm{C}$, the XRD pattern (e) was obtained.

incorporation in the film, ${ }^{9}$ in agreement with the results obtained by RBS and XPS.

In order to encourage epitaxial growth of BST, the substrate temperature was increased to $700{ }^{\circ} \mathrm{C}$. Stronger (111) orientation is observed in thicker films deposited at $700{ }^{\circ} \mathrm{C}$ [Figs. 3(b) and 3(c)]. A predeposition anneal of the substrate $^{10}$ was found to strongly increase the (111) orientation of the film, as shown in Fig. 3(d). Figure 3(e) shows XRD data for the same film as Fig. 3(d) after a $2 \mathrm{~h}$ postdeposition anneal in air at $900{ }^{\circ} \mathrm{C}$. Highly (111) oriented films have previously been observed in $\mathrm{Ba}_{0.1} \mathrm{Sr}_{0.9} \mathrm{TiO}_{3}$ films grown by metal-organic chemical vapor deposition (MOCVD) on $c$-plane sapphire substrates. ${ }^{11}$

BST (111) $\omega$ scans revealed a full width at half maximum (FWHM) of $\sim 7.7^{\circ}$ for the as-deposited film. After postdeposition annealing, the FWHM reduced to $\sim 4.9^{\circ}$. The XRD $\sin ^{2} \psi$ technique ${ }^{12,13}$ was employed to determine the effect of postdeposition annealing on the in-plane strain of the (111) textured film. Strain-free lattice parameters, calculated using the elastic data ${ }^{14}$ for BST $(x=0.5)$ were $3.984 \AA$ (as deposited) and $3.941 \AA$ (annealed). From these values, a tensile in-plane strain of $0.94 \%$ and compressive in-plane strain of $-0.38 \%$ were determined for the as-deposited and annealed films, respectively. As discussed by Chang et al., the stress field in the BST film is affected by the lattice and thermal coefficient mismatch between the film and substrate, and by film contraction on annealing due to oxygen incorporation. All of these factors may contribute to the sign change and reduced magnitude of stress observed here. The effect of annealing on the film grain size and surface roughness was investigated by atomic force microscopy (AFM; NT-MDT Solver LS). AFM images show an average grain size of $<100 \mathrm{~nm}$ (as deposited) and 100-150 nm (annealed). The annealing process also resulted in an increase in the average surface roughness $R_{a}$ from 2.7 to $5.9 \mathrm{~nm}$.

Microwave measurements were performed on an Anritsu 37369 A vector network analyzer (VNA). In order to deembed the parasitic inductance, capacitance, and resistance as- 


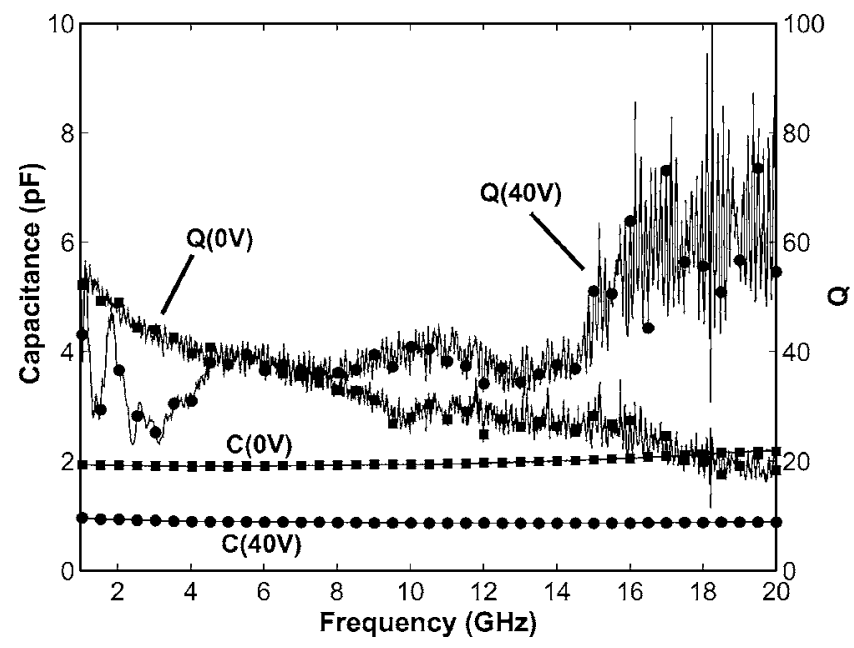

FIG. 4. Extracted capacitance and $Q$ factor from $1-20 \mathrm{GHz}$ at 0 and $40 \mathrm{~V}$ bias for $2 \mu \mathrm{m}$ gap interdigital capacitor.

sociated with the interdigital electrodes from the measured data, a set of open and short circuit calibration standards was patterned on the substrate adjacent to each IDC. ${ }^{15}$ The capacitance and $Q$ factor from $1-20 \mathrm{GHz}$ were determined by fitting the $S_{11}$ reflection data to an equivalent circuit model which included the pad parasitics. Due to the thick metal electrodes, the conductor losses were found to be negligible compared to the losses associated with the BST film. Bias was supplied to the IDCs via the internal bias tee on the VNA, and was therefore limited to $\pm 40 \mathrm{~V}$.

The initial series of samples deposited at $625^{\circ} \mathrm{C}$ showed limited capacitance tunability, defined as $\left(\mathrm{C}_{\max }-\mathrm{C}_{\min } / \mathrm{C}_{\max }\right)$ $\times 100$ of less than $2 \%$. A rapid thermal anneal in air at $\sim 800{ }^{\circ} \mathrm{C}$ for $60 \mathrm{~s} \mathrm{improved} \mathrm{the} \mathrm{tunability} \mathrm{to} 5 \%$. Increasing the deposition temperature to $700{ }^{\circ} \mathrm{C}$ and employing a predeposition anneal improved the capacitance tunability to $\sim 38 \%$. This higher tunability can be attributed to the strongly (111) textured film growth, shown in Fig. 3(d). Further improvement in tunability was achieved following a $2 \mathrm{~h}$ postdeposition anneal in air at $900{ }^{\circ} \mathrm{C}$. These results, presented in Fig. 4, show a capacitance tunability of $\sim 56 \%$ and $Q_{\min }$ of 25 at $10 \mathrm{GHz}$, for a bias field of $200 \mathrm{kV} / \mathrm{cm}$. The higher tunability was accompanied by an increase in the zero-bias dielectric constant $\varepsilon_{r}$ from 280 (as-deposited) to 520 (annealed), as determined by a conformal mapping technique. ${ }^{11,16}$ These results suggest that the increased grain size and strain relaxation observed following the annealing procedure contribute to the improved tunability. In a previously published result for a $100 \mathrm{~nm} \mathrm{Ba}_{0.7} \mathrm{Sr}_{0.3} \mathrm{TiO}_{3}$ thin film on $c$-plane sapphire, ${ }^{17}$ the tunability reported was $\sim 16 \%$ at $200 \mathrm{kV} / \mathrm{cm}$ bias.

In summary, we have demonstrated the growth of BST thin films with high tunability $(56 \%$ at $200 \mathrm{kV} / \mathrm{cm}$ bias field) and low loss $(Q>15$ up to $20 \mathrm{GHz})$ on (0001) sapphire substrates. The films deposited with a process gas pressure of 40 mTorr closely matched the target composition. Highly (111) textured films demonstrated improved tunability, while the best tunability was achieved following postdeposition annealing at $900{ }^{\circ} \mathrm{C}$. The enhanced tunability is attributed to strain relaxation and larger grain size observed in the film after annealing.

This work was supported by the CASS Foundation. The authors also wish to acknowledge the help of Dr. J. Du Plessis, Dr. K. Latham, and Prof. D. N. Jamieson.

${ }^{1}$ J. Im, O. Auciello, P. K. Baumann, S. K. Streiffer, D. Y. Kaufman, and A. R. Krauss, Appl. Phys. Lett. 76, 625 (2000).

${ }^{2}$ J. Bellotti, E. K. Akdogan, A. Safari, W. Chang, and S. K. Kirchoefer, Integr. Ferroelectr. 49, 113 (2002).

${ }^{3}$ P. Padmini, T. R. Taylor, M. J. Lefevre, A. S. Nagra, R. A. York, and J. S. Speck, Appl. Phys. Lett. 75, 3186 (1999).

${ }^{4}$ N. K. Pervez, P. J. Hansen, and R. A. York, Appl. Phys. Lett. 85, 4451 (2004).

${ }^{5}$ I. Bahl, Lumped Elements for RF and Microwave Circuits (Artech, Boston, 2003), Chap. 13, p. 398.

${ }^{6}$ O. Auciello, S. Saha, D. Y. Kaufman, S. K. Streiffer, W. Fan, B. Kabius, J. Im, and P. Bauman, J. Electroceram. 12, 119 (2004).

${ }^{7}$ V. Craciun and R. K. Singh, Appl. Phys. Lett. 76, 1932 (2000).

${ }^{8}$ Y. Fujisaki, Y. Shimamoto, and Y. Matsui, Jpn. J. Appl. Phys., Part 2 38, L52 (1999).

${ }^{9}$ W. Chang, J. S. Horwitz, A. C. Carter, J. M. Pond, S. W. Kirchoefer, C. M. Gilmore, and D. B. Chrisey, Appl. Phys. Lett. 74, 1033 (1999).

${ }^{10}$ J. A. Bellotti, Ph.D. thesis, Rutgers, The State University of New Jersey, 2003.

${ }^{11}$ D. Rafaja, J. Kub, D. Simek, J. Lindner, and J. Petzelt, Thin Solid Films 422, 8 (2002).

${ }^{12}$ I. C. Noyan and J. B. Cohen, Residual Stress (Springer, Berlin, 1987).

${ }^{13}$ B. M. Clemens and J. A. Bain, MRS Bull. 17, 46 (1992).

${ }^{14}$ Z.-G. Ban and S. P. Alpay, J. Appl. Phys. 93, 504 (2003).

${ }^{15}$ J. Park, J. Lu, S. Stemmer, and R. A. York, J. Appl. Phys. 97, 084110 (2005).

${ }^{16}$ S. S. Gevorgian, T. Martinsson, L. J. Linner, and E. L. Kollberg, IEEE Trans. Microwave Theory Tech. 44, 896 (1996).

${ }^{17}$ Y. Liu, A. S. Nagra, E. G. Erker, P. Periaswamy, T. R. Taylor, J. Speck, and R. A. York, IEEE Microw. Wirel. Compon. Lett. 10, 448 (2000). 